\title{
Política pública e gestão escolar: um estudo de caso no Rio de Janeiro ${ }^{1}$
}

\section{Public policy and school management: a case study in Rio de Janeiro}

\author{
Ana Cristina Prado de Oliveira²
}

\section{Resumo:}

Os estudos sobre a eficácia escolar têm ressaltado o efeito dos fatores intraescolares, entre eles o trabalho da gestão da escola, para a aprendizagem dos alunos. Neste artigo, analiso a tarefa da equipe gestora de gerenciar a aplicação das avaliações externas instituídas pelas políticas nacional e local. Tomo como referência os estudos sobre as escolas eficazes. A pesquisa empírica envolveu observação e entrevistas em uma escola do Rio de Janeiro. Os gestores demonstraram estratégias de adaptação às novas políticas avaliativas, mas ressaltamos excesso das novas demandas interferindo na rotina acadêmica da escola, ocasionando mudanças das funções do gestor.

Palavras-chave: Gestão escolar, Políticas Educacionais, Avaliação Educacional.

\begin{abstract}
:
Studies on school effectiveness have highlighted the effect of a school's characteristics, including the school's management, onthe students' learning. In this paper, I analyze the school's management team'stask ofsupervising the application of external tests introduced by new national and local policies. I use as reference previous studies about effective schools. The empirical research involved observation and interviews in a school in Rio de Janeiro.The school's managementdeveloped strategies to adapt to the new evaluation policies but underscored the interferenceof the incrementalworkloadon theschool's academic routine, with consequentchanges in the managers'responsibilities.
\end{abstract}

Keywords: School management, Educational Policies, Educational Evaluation.

1 Uma versão preliminar deste artigo foi apresentada no III Congresso Ibero Americano de Política e Administração da Escola, em Zaragoza, nov. 2012. Agências financiadoras: CNPq e Faperj.

2 Mestre em Educação e Doutoranda do programa de Pós-Graduação em Educação da Pontifícia Universidade Católica do Rio de Janeiro. E-mail: ana. prado.oliveira@gmail.com 


\section{Introdução}

Este trabalho propõe uma reflexão sobre a função da gestão escolar, considerando a relevância de seu papel para o bom funcionamento das funções acadêmicas na escola, como tem sido apontada pelos estudos sobre as escolas eficazes (BROOKE e SOARES, 2008). Entre suas muitas tarefas, inclui-se o acompanhamento e monitoramento da aprendizagem dos alunos através de instrumentos avaliativos. Como sabemos, atualmente vivenciamos no Brasil, e em particular na cidade do Rio de Janeiro, a aplicação de diferentes instrumentos avaliativos nas unidades escolares que atendem o Ensino Fundamental. Tornase importante, assim, verificar como os gestores têm gerenciado o levantamento, a administração e o monitoramento dos dados levantados por estas avaliações e qual o impacto destas novas atribuições no cotidiano de seu trabalho.

O presente artigo, fruto de uma pesquisa mais ampla, traz como questões norteadoras: 1) Qual é o papel do(s) gestor(es) enquanto mediador(es) das políticas avaliativas implementadas nas escolas? 2) Qual o efeito da introdução do gerenciamento de uma série de avaliações na sua rotina de trabalho?

O texto está organizado da seguinte forma: na primeira seção, apresento algumas informações sobre o cenário educacional atual no Brasil, considerando o contexto do surgimento dos mecanismos de avaliação da aprendizagem no Ensino Básico; na segunda seção, procuro discutir, a partir das contribuições dos estudos sobre as escolas eficazes, a importância da atuação da gestão escolar para os resultados acadêmicos dos alunos; já na terceira seção, apresento alguns dados da pesquisa desenvolvida, buscando relacionar os dois temas trabalhados nas seções anteriores, ou seja, como se dá a atuação da gestão na escola pesquisada, seus esforços para garantir os bons resultados alcançados e como esta atuação tem sido afetada pela introdução dos mecanismos de avaliação externa na rotina escolar; por fim, a quarta seção traz algumas conclusões a partir das questões levantadas e da reflexão acerca da realidade observada.

\section{Avaliando a aprendizagem no Ensino Fundamental: Prova Brasil, Prova Rio e Avaliações Bimestrais da Rede}

Experimentamos no Brasil, desde o início da década de 1990, mudanças significativas no que se refere à concepção de educação, relacionadas à avaliação, ao monitoramento e à busca pela eficácia escolar. Recentemente, o estabelecimento de parâmetros curriculares nacionais e outros mecanismos homogeneizadores, apontam "uma tentativa de atenuar a grande diversidade de padrões e de garantir os níveis mínimos de qualidade previstos na Constituição e na Lei de Diretrizes e Bases da Educação Nacional" (BROOKE, 2006, p. 385).

Contamos hoje, no Brasil, com coleta e disponibilização de dados educacionais nunca antes experimentadas e o trabalho com a análise dessas informações começa a se estruturar de forma mais regular e sistematizada.

De acordo com Oliveira e Araújo (2005), a qualidade da educação foi analisada associada às medidas de 1) acesso; 2) fluxo e 3) desempenho na recente história educacional em nosso país. As políticas educacionais refletem estas associações, definindo a agenda de prioridades para as redes de ensino e o papel esperado dos gestores e agentes educacionais. Assim, atualmente, medir a melhoria do ensino básico significa analisar, para além do acesso e fluxo, "a elevação dos níveis de aprendizado dos alunos, medido em escalas especificamente desenvolvidas para esse fim" (SOARES, 2007, p. 138). Em 1990 foi criado o Sistema de Avaliação da Educação Básica (SAEB), e em 2005, o Ministério da Educação (MEC) propôs uma ampliação do monitoramento da aprendizagem no Ensino Fundamental, instituindo a Prova Brasil. Assim, são aplicados testes de Língua Portuguesa e Matemática a todos os alunos das séries finais 
de cada segmento do Ensino Fundamental ( $5^{\circ}$ e $9^{\circ}$ anos) em todas as escolas da rede pública de ensino do país com mais de 20 estudantes matriculados por série alvo da avaliação. Sua intenção diagnóstica é defendida pelo Plano de Metas Todos pela Educação:

Com os resultados do Prova Brasil, as secretarias e o MEC têm um diagnóstico da Educação brasileira, podendo detectar desigualdades nas escolas e entre elas. A partir disso, esses órgãos devem definir ações e direcionar recursos para corrigir essas distorções e melhorar a qualidade do ensino. ${ }^{3}$

Os resultados desses instrumentos de avaliação, juntamente com os dados referentes ao fluxo nas escolas, foram posteriormente consolidados através do Índice de Desenvolvimento da Educação Básica (IDEB). A taxa do IDEB referente a cada escola, ao município, ao estado ou ao país, é calculada a partir de dois componentes: a taxa do fluxo escolar (aprovação), coletada no Censo Escolar, e as médias de desempenho dos alunos nos exames da Prova Brasil, para escolas e municípios, e do SAEB, para os estados e o País, testes que são realizados a cada dois anos.

O objetivo principal deste monitoramento, segundo o MEC (BRASIL, 2007), é que o Brasil conquiste 6 pontos no IDEB da primeira etapa do Ensino Fundamental até 2022, nota média dos estudantes dos países da Organização para a Cooperação e Desenvolvimento Econômico (OCDE). De acordo com o Plano de Desenvolvimento da Educação (PDE), estados, municípios e escolas deverão melhorar seus índices e contribuir, em conjunto, para que o Brasil chegue ao resultado esperado.

A busca por atingir as metas estabelecidas pelo governo federal gerou iniciativas localizadas de avaliação do ensino público, como as experimentadas em Minas Gerais, São Paulo e Rio de Janeiro. No município do Rio de Janeiro, contexto desta pesquisa, a atual gestão da Secretaria Municipal de Educação (SME) implantou, a partir de 2009, uma nova política educacional, em consonância com a política nacional, instituindo duas novas modalidades avaliativas: a Prova Rio e as Avaliações Bimestrais da Rede. A Prova Rio é uma avaliação anual através de testes que seguem os moldes da Prova Brasil, ou seja, é composta de testes de múltipla escolha que abrangem as áreas de Matemática e Língua Portuguesa. A Secretaria Municipal de Educação (SME) instituiu um processo de preparação para a Prova Rio que envolve, além do ensino dos conteúdos a serem testados nas avaliações, exercícios e correções, instrumentalização para o preenchimento do documento, a realização de simulados nas séries que serão avaliadas. Os simulados são testes aplicados também anualmente pela SME, que seguem os padrões das avaliações externas como treinamento para a Prova Rio.

Além da Prova Rio, a atual gestão da SME também instituiu as Avaliações Bimestrais da Rede, que são testes de múltipla escolha de Língua Portuguesa, Matemática e Ciências, aplicados a todas as séries do Ensino Fundamental bimestralmente. Seus resultados são monitorados pela SME e compõem a nota média escolar do aluno. Essas avaliações estão articuladas a dois outros instrumentos didáticos introduzidos pela mesma política: os Descritores de Ensino (listas bimestrais de habilidades e conteúdos a serem contemplados nas Avaliações Bimestrais da Rede) e os Cadernos de Apoio Pedagógico (apostilas bimestrais de exercícios das disciplinas avaliadas que visam complementar o trabalho do professor e preparar os alunos para a Avaliação Bimestral da Rede).

Essa nova organização educacional com todos seus instrumentos e demandas chega ao contexto escolar e altera significativamente sua rotina. Como os educadores incorporam estes instrumentos em sua prática? Como lidam com o desafio de gerenciar tais mudanças? O que cabe à gestão da escola neste contexto? Para pensar essas questões, busco refletir, na próxima seção, sobre a relação entre a gestão e a eficácia escolar.

3 Disponível em: www.todospelaeducacao.org.br/educacao-no-brasil . Acesso em: 12 jul. 2011. 


\section{A gestão da escola como condição para a eficácia escolar}

O termo "eficácia escolar" vem sendo comumente empregado nos contextos educacionais, especialmente das políticas públicas, para designar algo que produziria resultados positivos em se tratando da função principal da escola: ensinar, independentemente da origem social dos alunos. Nesse sentido, de acordo com Gomes (2005), uma escola eficaz seria aquela que fosse, "ao mesmo tempo, de qualidade e democrática, isto é, que não ofereça aos pobres uma escolaridade pobre, mas que efetivamente consiga que os alunos, mesmo socialmente desprivilegiados, aprendam" (p.282). Brooke e Soares (2008, p.10) alertam para o fato do uso da terminologia por autoridades educacionais e pesquisadores de forma precipitada, recorrendo a estudos externos sem a devida contextualização. Os autores buscaram, recentemente, traçar a trajetória das pesquisas nesta linha, apresentando estudos internacionais e locais sobre a eficácia escolar, organizando-os de maneira histórica a fim de dar visibilidade à evolução do pensamento nessa área, desde o surgimento da pesquisa direcionada à eficácia escolar ("Relatório Coleman") até o início da mesma no Brasil. Os autores esclarecem que as pesquisas na área também utilizam o termo estudo do efeito-escola para identificar as pesquisas sobre escolas eficazes:

Por efeito-escola entende-se 0 quanto um dado estabelecimento escolar, pelas suas políticas e práticas internas, acrescenta ao aprendizado do aluno. Essa definição enfatiza a ideia de que cada escola deve ser analisada a partir dos resultados de seu processo de ensino-aprendizagem e que os fatores associados com melhores resultados devem ser identificados (BROOKE e SOARES, 2008, p. 10).

Os estudos sobre a eficácia escolar vêm tentando determinar qual é o efeito das experiências vivenciadas na escola (que são particulares e relativas às características da instituição) para a aprendizagem dos alunos. Assim, controlando as especificidades iniciais dos alunos (origem socioeconômica, raça, organização familiar...) os estudos buscam aferir quais são os fatores estruturais e organizacionais das escolas associados a diferentes resultados acadêmicos entre elas, ou seja, entre escolas que atendem alunos com perfis semelhantes, o que têm aquelas que apresentam melhores resultados acadêmicos e como fazem para alcançá-los.

Sammons (2008, p.336) levantou onze "características-chave das escolas eficazes", relacionados à estrutura da escola, aspectos da gestão, valorização de um ambiente organizado para a aprendizagem e estratégias do professor. Alves e Franco (2008, p.494) resumem tais fatores associados à escola eficaz em cinco categorias para o caso brasileiro: recursos escolares, organização e gestão da escola, clima acadêmico, formação e salário docente e ênfase pedagógica. Ambos os trabalhos, assim como a literatura sobre o tema, apontam a gestão escolar entre os fatores intraescolares que podem influenciar positivamente o desempenho do aluno e a eficácia escolar. Soares (2007, p.153), a partir da proposição de um modelo conceitual para abordar o processo de aprendizagem em uma perspectiva multidisciplinar, considera que: "dentro da escola há dois importantes processos que interagem para a produção do desempenho dos alunos: a gestão escolar e o ensino". De acordo com o autor, a gestão da escola, liderada pelo(a) diretor(a), compreende as tarefas relativas à garantia do funcionamento da escola no que se refere à rotina de funcionamento "de forma que os recursos nela existentes possam ser usados para atender às necessidades de aprendizagem dos alunos" (SOARES, 2007, p.153). Isto envolve tarefas rotineiras, como acompanhar e efetivar a assiduidade de alunos e professores, identificar os problemas de aprendizagem e buscar recursos para saná-los, estabelecer contatos com as famílias dos alunos em prol de seu acompanhamento escolar, garantir o acesso de alunos e professores aos materiais didáticos necessários para o trabalho escolar, entre outras. Soares (2007, p.154) aponta uma importante tarefa, geralmente a cargo da gestão escolar, que pode ter alto impacto no aproveitamento dos alunos: a enturmação - processo de distribuição dos alunos nas diferentes turmas em cada série /ano. 
As diferenças encontradas nos resultados positivos dos alunos que poderiam se relacionar ao trabalho da gestão da escola geralmente estão vinculadas ao cumprimento das tarefas descritas acima, conciliando a manutenção de um ambiente propício para a aprendizagem e um trabalho coletivo de visão e metas compartilhadas entre a equipe (características das escolas eficazes, apontadas pela literatura).

Entre as tarefas que compõem o trabalho do gestor na escola, voltamos nossa atenção, neste momento para o monitoramento da aprendizagem dos alunos, através do acompanhamento dos processos avaliativos internos e externos.

Por esta razão, interessou-nos analisar, especialmente como o estabelecimento de avaliações externas impacta o trabalho da gestão na escola e quais são os mecanismos que os gestores lançam mão para garantir um trabalho eficaz na escola nesse contexto. Na próxima seção, apresento os dados de uma pesquisa que apontam pistas para essas questões.

\section{As avaliações e a gestão em contexto: a experiência de uma escola do Rio de Janeiro}

Os dados que apresento a seguir se referem a uma pesquisa ${ }^{4}$ desenvolvida durante os anos de 2010 e 2011, que tinha uma abrangência maior do que as questões levantadas neste artigo. O recorte ora apresentado buscou direcionar a análise dos dados para o trabalho da gestão da escola em um contexto de superposição de políticas (dos governos Federal e Municipal).

A pesquisa foi realizada em uma escola da Zona Sul da cidade do Rio de Janeiro, selecionada por apresentar bons resultados em seguidas edições da Prova Brasil, tornando-se uma referência de "boa escola" no bairro e para a comunidade que atende. Metodologicamente, o trabalho envolveu um longo período de observação das reuniões pedagógicas semanais e de planejamento anual, além de entrevistas com professores e com a equipe de gestão da escola, composta pela Diretora, a Diretora Adjunta e a Coordenadora Pedagógica.

Durante o trabalho de campo, esta equipe demonstrou trabalhar de forma bastante integrada, como foi observado nas situações rotineiras e é referenciado em seus depoimentos. Entre as atividades da escola a cargo da gestão, a Diretora se ocupa prioritariamente daquelas relacionadas à administração financeira (alocação dos recursos, ordens de compras, prestação de contas, entre outras), além de participar de todas as reuniões coletivas com os responsáveis pelos alunos e do atendimento às famílias que apresentam casos mais complexos a serem tratados. As demandas referentes à gestão pedagógica da escola, entre elas o acompanhamento e monitoramento da aprendizagem dos alunos e o suporte ao trabalho docente, ficam a cargo da Diretora Adjunta e da Coordenadora, motivo pelo qual elas serão as principais referências neste estudo representando a gestão da escola.

A Coordenadora Pedagógica conta com a parceria constante da Diretora Adjunta e demonstram sintonia nas orientações e na articulação do trabalho com os professores. Ambas atuaram como professoras nesta mesma instituição, fazendo com que o coleguismo estabelecido na trajetória profissional anterior facilitasse a comunicação com os professores.

Nos Centros de Estudos (CEs) e Conselhos de Classe (COCs), conforme registrado nas planilhas de observação, a Coordenadora Pedagógica e a Diretora Adjunta apresentavam ou retomavam as demandas referentes às datas ou providências relacionadas às políticas curriculares da Secretaria Municipal de Educação - SME ou às avaliações externas de maneira neutra, sem julgamento ou crítica, argumentando que esta era a demanda atual para todas as escolas e teria de ser cumprida. Demonstravam, dessa forma, uma aceitação das normas estabelecidas, embora em seus depoimentos sempre tenham ressaltado que o trabalho da escola ia além do cumprimento das metas estipuladas externamente.

4 Refiro-me à pesquisa que deu origem à Dissertação de Mestrado intitulada "Política pública e prática docente: quando e como dialogam no espaço escolar - A experiência de uma escola do Rio de Janeiro" (OLIVEIRA, 2011). 
A pesquisa se deu em um momento muito significativo para pensar a atuação da gestão nas escolas municipais do Rio de Janeiro, uma vez que a instituição dos instrumentos avaliativos mencionados era muito recente. Nesse momento de adaptação a uma nova política, a gestão da escola teve o importante papel de mediar a relação entre a SME e os professores. São elas, a Coordenadora e/ou as Diretoras, que participam das reuniões na Coordenadoria Regional de Ensino (CRE) $)^{5}$, se responsabilizando por informar os demais agentes escolares sobre as demandas apontadas e fazê-las cumprir. Na escola pesquisada, a Diretora Adjunta e a Coordenadora desempenham essa interseção entre a SME e a equipe de professores, buscando esclarecer a nova política da rede e garantir o funcionamento da escola, como exemplifico nos extratos a seguir:

Com relação aos Descritores da SME/RJ para $04^{0}$ bimestre, outro tópico da pauta, a Coordenadora informa que eles já estão disponíveis. Neste momento, como algumas professoras pareciam ainda confusas com relação à associação entre Descritores, Cadernos de Apoio Pedagógico e Provas, a Diretora Adjunta e a Coordenadora esforçam-se em esclarecer todas as dúvidas. Reafirmam que as Provas Bimestrais da SME seguem os Descritores propostos pela SME, é por eles que os alunos devem ser preparados. Comentam que 0 Simuladão da SME, sobre 0 qual distribui uma circular para as professoras de $3^{\circ}, 4^{\circ}$ e $5^{\circ}$ anos, foi criado para familiarizar o aluno com o tipo de prova proposto pela Prova Rio: "Os descritores para a Prova Rio são os mesmos da Prova Brasil e do SAEB".

A Coordenadora esclarece novamente sobre as avaliações externas:

"Prova Brasil: define o IDEB, a partir deste resultado a prefeitura do Rio premia as escolas a cada dois anos. É para os alunos do $5^{\circ}$ ano e é bienal, este ano tem Provinha Brasil: esse ano terá o controle com o $2^{\circ}$ ano.Prova Rio: define o IDE-Rio, também está vinculado à premiação pela SME. Vai avaliar alunos do $5^{\circ}$ ano em 2012" (Trechos do Diário de Campo de 18/05/2011, Centro de Estudo).

É interessante ressaltar que durante as explicações ao grupo sobre as orientações da SME sobre o currículo e as avaliações externas, a Diretora Adjunta e a Coordenadora foram extremamente claras e objetivas, apresentando as informações com a segurança de quem está familiarizado com o assunto. Alguns esclarecimentos são repetidos mais de uma vez para o grupo de professores o que pareceu ser fundamental para evitar qualquer risco de confusão, em um momento em que várias novidades eram incorporadas à rotina do professor.

Entre as atribuições da Coordenação Pedagógica e da Direção da escola, incluiu-se a preparação dos alunos para as avaliações externas. Nesse contexto escolar, os alunos também fazem simulados internos, preparados pelos professores nos moldes das questões das Avaliações Bimestrais da Rede.

Preocupada com a realização da Prova Brasil pelos alunos do $5^{\circ}$ ano, a Diretora Adjunta e a Coordenadora da escola instruíram as professoras a realizarem com seus alunos as questões das edições anteriores:

[...] percebemos que os professores do quinto ano tinham dificuldade, porque chegava na hora da prova os alunos não conseguiam fazer. Então o que fizemos de proposição? Entrou até como meta do nosso Projeto Pedagógico, que é esse trabalho com provas anteriores do Governo Federal, da Prova Brasil, durante 0 ano todo. Que isso fosse uma rotina durante 0 ano todo: a questão da interpretação dos enunciados da prova (Trecho da entrevista com a Coordenadora realizada em 24 ago. 2011).

A Coordenadora também buscava tabular os erros das Avaliações Bimestrais da Rede para fazer um levantamento das questões que mereceriam um investimento maior do professor:

[...] eu até faço isso para ajudar o professor, de cada ano eu vejo as questões mais erradas, faço uma lista, passo para os professores. A orientação é de que eles revejam essa questão porque se grande parte da turma errou, algum nó tem ali. Pode ser até um nó de uma palavra que eles não conheçam no enunciado. (idem)

5 A rede de escolas municipais do Rio de Janeiro é a maior da América Latina, composta de 1.068 escolas, 250 creches pública, 65 EDls e outras 179 creches conveniadas. Com cerca de 38 mil professores, a SME atende a 685.279 alunos. Este extenso volume estava dividido, nesta data, em 10 Coordenadorias Regionais de Ensino (CREs) de acordo com a localização geográfica das unidades de ensino. 
Ball (2001) considera que "durante os últimos vinte anos, a gestão tem sido um mecanismo chave, tanto na reforma política quanto na reengenharia cultural no setor público [...] Enquanto os mercados trabalham de fora para dentro, a gestão funciona de dentro para fora" (p.108). Nesse sentido, o papel de mediação entre a SME e os professores vem sendo desempenhado pela equipe de gestão da escola. Em alguns momentos, o seu trabalho foi garantir que as demandas da SME estavam sendo trabalhadas pelos professores, como podemos conferir nos extratos abaixo:

0 professor tem a organização de sua sala de aula. Eu não passo e fico conferindo o que o professor "deu", mas ele sabe que no final do bimestre ele tem que dar conta do conteúdo porque vem a prova da SME e ele vai ser cobrado...

Ah... é chato? Não... temos que pensar que isso é importante para a melhoria da escola, do trabalho... (Trechos do Diário de Campo de 03/02/2011, Semana Pedagógica, falas da Diretora Ajunta).

Apesar do papel de destaque que os gestores recebem nas atuais políticas educacionais, cabendo-lhes o controle e o monitoramento de metas e resultados, pode-se observar uma descaracterização nas funções pedagógicas das pessoas que exercem a gestão da escola, através da introdução de tarefas mais burocráticas do que pedagógicas.

A Coordenadora Pedagógica exemplifica, em seu depoimento, algumas das alterações nas suas funções:

Eu acho que hoje é a cobrança de resultado, de planilha, de projetos... é muita coisa ao mesmo tempo e você acaba não dando tempo de tudo, ou você coordena ou você organiza, ou você manda planilha... [...] São muitas demandas, reuniões.... [...] Quando eu estou no computador eu estou fazendo coisa que está sendo cobrada, mais burocrática do que pedagógica... Os coordenadores são administradores, na verdade, de alunos, de papéis e de resultados e de cobranças [grifo meu] (Trecho da entrevista com a Coordenadora, realizada em 24 ago. 2011).

A Diretora Adjunta também se mostra preocupada com a organização da rotina na escola, com as formas encontradas pelos professores para conciliar o seu planejamento, o Projeto Político Pedagógico da escola e o calendário repleto de avaliações:

0 professor hoje se vê muito preso de muita avaliação. Porque tem a avaliação semestral, aí vem o simulado para a avaliação, aí vem a testagem para ver a sondagem, num intervalo pequeno de tempo. Está faltando tempo para se trabalhar o conteúdo para a prova. 0 professor se desespera, entre aspas, porque ele não consegue aprofundar os conhecimentos que eles lançam para os alunos. Então, a administração do tempo tem de ser revista, esse monte de simulado do simulado do simulado... e eu acho que está faltando a escola poder respirar um pouco para trabalhar os seus projetos pedagógicos internos. Quando eu comecei na coordenação a gente começou a trabalhar com projetos e foi crescendo a cada ano... agora deu uma parada porque não se encontra tempo pedagógico para trabalhar as questões interdisciplinares (Trecho da entrevista com a Diretora Adjunta realizada em 13/10/2011).

A análise dos dados permitiu inferir que a equipe que exerce a gestão nesta escola reconhece e desempenha o seu papel de articulação das políticas educacionais junto aos professores, procurando garantir o cumprimento de prazos e metas, demonstrando uma busca de eficiência no trabalho e a preocupação com a manutenção dos bons resultados. Há, de certa forma, uma adesão às políticas avaliativas e suas implicações, interpretadas como caminho a ser percorrido para garantir o sucesso dos alunos nos testes que serão realizados. Assim, a equipe de gestão da escola pesquisada reconhece as mudanças trazidas pela instituição das avaliações em sua rotina de trabalho - que incluem o aumento de serviço burocrático, o cuidado no controle dos dados relativos às avaliações, bem como o monitoramento do trabalho do professor na preparação para os testes - e as desempenha com cuidado e rigor, procurando garantir com que os professores também incorporem em sua rotina esse compromisso. Apesar do desgaste e da pressão que dizem sofrer com tantas demandas e com a preocupação em atingir os resultados esperados, a equipe de gestão valoriza a necessidade do monitoramento da aprendizagem nas escolas e realiza seu trabalho de maneira a corresponder às expectativas que sua unidade de ensino construiu acerca de si própria e não apenas às expectativas externas. 


\section{Conclusão}

Como os estudos sobre as escolas eficazes têm buscado demonstrar, "está muito claro que há, hoje, um amplo espaço para a ação nas estruturas escolares com vista à melhoria do desempenho dos alunos da educação fundamental brasileira" (SOARES, 2007, p. 156). Entre os fatores escolares que podem influenciar positivamente a aprendizagem dos alunos, como vimos, está o trabalho da gestão. O impacto que exerce na melhora dos resultados acadêmicos dos alunos não se dá de maneira direta, mas envolve um verdadeiro trabalho de bastidores, estreitamente relacionado a garantir que outras características apontadas como essenciais para a eficácia escolar (SAMMONS, 2008, p.351) estejam presentes: objetivos e visões compartilhados, ambiente de aprendizagem, incentivos positivos, parceria casa-escola, organização orientada à aprendizagem e monitoramento do progresso. Entre as tarefas da gestão, enfoquei neste trabalho àquelas relacionadas ao monitoramento do progresso dos alunos através da aplicação e acompanhamento das avaliações externas que hoje fazem parte do calendário escolar dos alunos que frequentam o Ensino Fundamental.

As determinações das políticas públicas, como as que instituem avaliações externas para acompanhar o trabalho desenvolvido nas escolas, dependem, em sua maioria, da articulação do trabalho da gestão para chegar até ao professor e à sala de aula. Como foi exposto pelos dados da pesquisa, a mediação realizada pela equipe gestora da escola, entre as determinações da SME e o trabalho dos professores, foi fundamental para o bom andamento do mesmo. Muitas dúvidas surgiam na organização do calendário de avaliações e no cumprimento das questões burocráticas que envolviam a aplicação das avaliações e cabia à gestão da escola esclarecer e direcionar o trabalho.

Entre as mudanças trazidas para o trabalho dos gestores a partir da aplicação das avaliações mencionadas, destacamos: reorganizar o calendário e a rotina da escola, alterando horários e salas para a aplicação de provas, esclarecer dúvidas e instruir os professores sobre os instrumentos, prazos e demandas de cada avaliação, monitorar, publicar e comparar os resultados dos alunos, propor estratégias de recuperação para os alunos com dificuldades e de revisão para as questões com grande índice de erro. Há, então, a introdução de novas demandas no trabalho desenvolvido pela gestão da escola e as queixas apresentadas no ambiente investigado se referem ao excesso de avaliações para os alunos do município do Rio de Janeiro e ao enfoque mais burocrático do trabalho do gestor. Contudo, incorporam as novas atribuições em sua rotina, buscando desempenhá-las de acordo com o que Ihes é determinado e com o compromisso em manter os bons resultados que a escola atingiu. Talvez estas sejam mais algumas características de uma gestão comprometida com a eficácia escolar: a capacidade de adaptação às mudanças e a pro-atividade frente aos desafios. Busquei neste artigo levantar algumas impressões sobre a relação entre o trabalho da gestão e a introdução de novas avaliações externas na escola, levando em consideração os dados levantados em trabalho anterior. Tais impressões se configuram em direções para novas pesquisas sobre o tema que, acredito, merece maior aprofundamento. 


\section{Referências Bibliográficas}

ALVES, M. T. G. e FRANCO, C. A pesquisa em eficácia escolar no Brasil: evidências sobre o efeito das escolas e fatores associados à eficácia escolar. In: BROOKE, Nigel; SOARES, José Francisco. (Orgs.) Pesquisa em eficácia escolar: origem e trajetórias. Belo Horizonte: Editora UFMG, 2008.

BALL, S. Diretrizes Políticas Globais e Relações Políticas Locais em Educação. Currículo Sem Fronteiras, v.1, n.2, p. 99-116, jul./dez. 2001. Disponível em: <http://www.curriculosemfronteiras.org/artigos.htm>. Acesso em: 12 maio 2010.

BRASIL. Ministério da Educação. IDEB - Índice de Desenvolvimento da Educação Básica. Brasília: MEC, SEB; Inep, 2007. Disponível em: <http://portal.mec.gov.br/index> Acesso em: 11 dez. 2011.

. Ministério da Educação. PDE : Prova Brasil - ensino fundamental : matrizes de referência, tópicos e descritores. Brasília: MEC, SEB; Inep, 2008. Disponível em:<http://portal.mec.gov.br/dmdocuments/prova\%20 brasil_matriz2.pdf> Acesso em: 11 dez. 2011.

BROOKE, N. O futuro das políticas de responsabilização educacional no Brasil. Cadernos de Pesquisa, São Paulo, v. 36, n. 128, p.377-401, maio/ago. 2006. Disponível em <http://www.scielo.br/scielo>. Acesso em: 20 out. 2011.

BROOKE, N.; SOARES, J. F. (Orgs.) Pesquisa em eficácia escolar: origem e trajetórias. Belo Horizonte: Editora UFMG, 2008.

GOMES, C. A. A Escola de Qualidade para Todos: Abrindo as Camadas da Cebola. Ensaio: Avaliação e Políticas Públicas em Educação. Rio de Janeiro, v.13, n.48, p. 281-306, jul./set. 2005.

OLIVEIRA, A. C. P. Política pública e prática docente: quando e como dialogam no espaço escolar: a experiência de uma escola do Rio de Janeiro. Dissertação (Mestrado)-Pontifícia Universidade Católica do Rio de Janeiro, Departamento de Educação, 2011.

OLIVEIRA, R. P.; ARAUJO, G.C. Qualidade do ensino: uma nova dimensão da luta pelo direito à educação. Revista Brasileira de Educação. № 28, já./fev./mar./abr, 2005, p. 5-23.

SAMMONS, P. As características-chave das escolas eficazes. In: BROOKE, Nigel; SOARES, J. F. (Orgs.) Pesquisa em eficácia escolar: origem e trajetórias. Belo Horizonte: Editora UFMG, 2008.

SOARES, J. F. Melhoria do desempenho cognitivo dos alunos do ensino fundamental. Cadernos de Pesquisa, São Paulo, v. 37, n. 130, p. 135-160, jan./abr. 2007. Disponível em: <http://www.scielo.br/scielo>. Acesso em 09 jun. 2011.

Recebido em Abril de 2013 Aprovado em Dezembro de 2013 